THE SOCIAL MEDICINE READER

Volume 1, Third Edition 
This page intentionally left blank 


\section{THE SOCIAL MEDICINE READER}

VOLUME

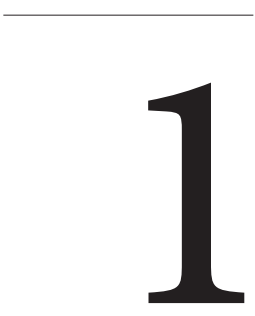

THIRD EDITION

Ethics and Cultures of Biomedicine

Jonathan Oberlander, Mara Buchbinder, Larry R. Churchill,

Sue E. Estroff, Nancy M. P. King, Barry F. Saunders,

Ronald P. Strauss, and Rebecca L. Walker, eds. 
(C) 2019 Duke University Press

All rights reserved

Printed in the United States of America

on acid-free paper $\infty$

Designed by Matthew Tauch

Typeset in Minion Pro by Westchester

Publishing Services

Library of Congress Cataloging-in-Publication Data

Names: Oberlander, Jonathan, editor.

Title: The social medicine reader / Jonathan

Oberlander, Mara Buchbinder, Larry R. Churchill,

Sue E. Estroff, Nancy M. P. King, Barry F. Saunders,

Ronald P. Strauss, Rebecca L. Walker, editors.

Description: Third edition. | Durham : Duke

University Press, 2019- | Includes bibliographical

references and index.

Identifiers: LCCN 2018044276 (print)

LCCN 2019000395 (ebook)

ISBN 9781478004356 (ebook)

ISBN 9781478001737

ISBN 9781478001737 (v. 1 ; hardcover ; alk. paper)

ISBN 9781478002819 (v. 1 ; pbk. ; alk. paper)

Subjects: LCSH: Social medicine.

Classification: LCC RA418 (ebook) | LCC RA418 .s6424

2019 (print) | DDC 362.1-dc23

LC record available at https://lccn.loc.gov/2018044276 